\title{
Solubility Limits of Dibutyl Phosphoric Acid in Uranium Solutions at SRS
}

by

M. C. Thompson

Westinghouse Savannah River Company

Savannah River Site

Aiken, South Carolina 29808

R. A. Pierce

R. J. Ray

This paper was prepared in connection with work done under the above contract number with the U. S.

Department of Energy. By acceptance of this paper, the publisher and/or recipient acknowledges the U.S. Government's right to retain a nonexclusive, royalty-free license in and to any copyright covering this paper, along with the right to reproduce and to authorize others to reproduce all or part of the copyrighted paper.

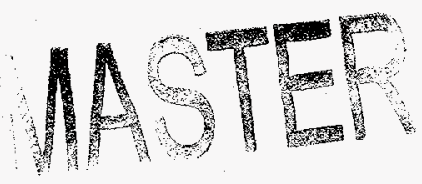




\section{DISCLAIMER}

This report was prepared as an account of work sponsored by an agency of the United States Government. Neither the United States Government nor any agency thereof, nor any of their employees, makes any warranty, express or implied, or assumes any legal liability or responsibility for the accuracy, completeness, or usefulness of any information, apparatus, product, or process disclosed, or represents that its use would not infringe privately owned rights. Reference herein to any specific commercial product, process, or service by trade name, trademark, manufacturer, or otherwise does not necessarily constitute or imply its endorsement, recommendation, or favoring by the United States Government or any agency thereof. The views and opinions of authors expressed herein do not necessarily state or reflect those of the United States Government or any agency thereof.

This report has been reproduced directly from the best available copy.

Available to DOE and DOE contractors from the Office of Scientific and Technical Information, P.O. Box 62, Oak Ridge, TN 37831; prices available from (615) 576-8401.

Available to the public from the National Technical Information Service, U.S. Department of Commerce, 5285 Port Royal Road, Springfield, VA 22161. 


\section{DISCLAIMER}

Portions of this document may be illegible electronic image products. Images are produced from the best available original document. 
WESTINGHOUSE SAVANNAH RIVER COMPANY

SAVANNAH RIVER TECHNOLOGY CENTER

Solubility Limits of Dibutyl Phosphoric Acid in Uranium Solutions at SRS (U)

R. A. Pierce, M. C. Thompson, and R. J. Ray

June 1, 1998 
WESTINGHOUSE SAVANNAH RIVER COMPANY

SAVANNAH RIVER TECHNOLOGY CENTER

\section{Solubility Limits of Dibutyl Phosphoric Acid in Uranium Solutions at SRS (U)}

R. A. Pierce, M. C. Thompson, and R. J. Ray

Technical Review:
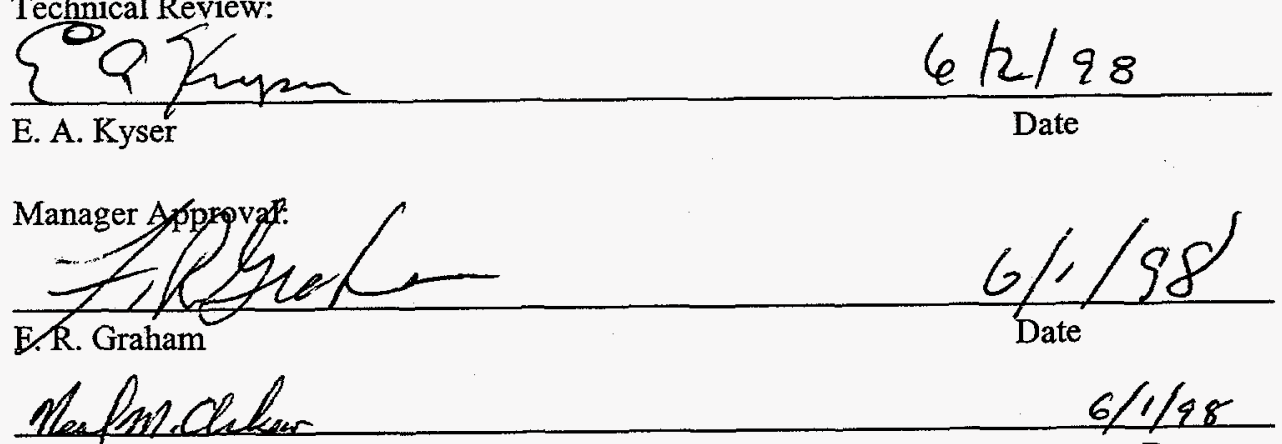

Date 


\begin{abstract}
The Savannah River Site has enriched uranium (EU) solution which has been stored for almost 10 years since being purified in the second uranium cycle of the $\mathrm{H}$ area solvent extraction process. The concentrations. in solution are $\sim 6 \mathrm{~g} / \mathrm{L} \mathrm{U}$ and about $0.1 \mathrm{M}$ nitric acid. Residual tributylphosphate in the solutions has slowly hydrolyzed to form dibutyl phosphoric acid (HDBP) at concentrations averaging $50 \mathrm{mg} / \mathrm{L}$. Uranium is known to form compounds with DBP which have limited solubility. The potential to form uranium-DBP solids raises a nuclear criticality safety issue.
\end{abstract}

SRTC tests have shown that U-DBP solids will precipitate at concentrations potentially attainable during storage of enriched uranium solutions. Evaporation of the existing EUS solution without additional acidification could result in the precipitation of U-DBP solids if DBP concentration in the resulting solution exceeds $110 \mathrm{ppm}$ at ambient temperature. The same potential exists for evaporation of unwashed 1CU solutions. The most important variables of interest for present plant operations are $\mathrm{HNO}_{3}$ and $\mathrm{DBP}$ concentrations. Temperature is also an important variable controlling precipitation. The data obtained in these tests can be used to set operating and safety limits for the plant. It is recommended that the data for $0^{\circ} \mathrm{C}$ with $0.5 \mathrm{M} \mathrm{HNO}_{3}$ be used for setting the limits. The limit would be $80 \mathrm{mg} / \mathrm{L}$ which is 3 standard deviations below the average of 86 observed in the tests. The data shows that super-saturation can occur when the DBP concentration is as much as $50 \%$ above the solubility limit. However, super-saturation cannot be relied on for maintaining nuclear criticality safety.

The analytical method for determining DBP concentration in U solutions was improved so that analyses for a solution are accurate to within $10 \%$. However, the overall uncertainty of results for periodic samples of the existing EUS solutions was only reduced slightly. Thus, sampling appears to be the largest portion of the uncertainty for EUS sample results, although the number of samples analyzed here is low which could contribution to higher uncertainty. The analytical method can be transferred to the plant analytical labs for more routine analysis of samples. 


\section{Table of Contents}

Introduction

Experimental

Precipitation Tests

Solids Dissolution

Analysis

Results and Discussion

Conclusions and Recommendations

References

\section{List of Figures and Tables}

Figure 1. U-DBP Solubility vs. Temp. - $0.1 \mathrm{M} \mathrm{HNO}_{3}$

Figure 2. U-DBP Solubility vs. Temp. - $0.5 \mathrm{M} \mathrm{HNO}_{3}$

Figure 3. U-DBP Solubility vs. Acid Concentration $-10^{\circ} \mathrm{C}$

Figure 4. U-DBP Solubility vs. Acid Concentration $-30^{\circ} \mathrm{C}$

Table 1. Solution Preparation for First 0C Temperature Tests

Table 2. Solution Preparation for Second 0C Temperature Tests

Table 3. Solution Preparation for Ambient Temperature Tests

3

Table 4. Solution Preparation for Solid Dissolution

4

Table 5. Analytical Results for Standard Samples

Table 6. Replicate Analyses of Plant EUS Samples

Table 7. Combined Error for EUS Samples 


\section{Introduction}

The Savannah River Site has enriched uranium (EU) solution which has been stored for almost 10 years since being purified in the second uranium cycle of the $\mathrm{H}$ area solvent extraction process. The concentrations in solution are $\sim 6 \mathrm{~g} / \mathrm{L} \mathrm{U}$ and about $0.1 \mathrm{M}$ nitric acid. After reprocessing, the solution contained about $200 \mu \mathrm{g}$ of dissolved tributyl phosphate (TBP) per gram of solution and a thin film of 7.5 vol.\% TBP in n-paraffin diluent floating on top of the solution. The dissolved TBP has slowly hydrolyzed to dibutyl phosphoric acid (DBP) giving an average concentration of DBP in solution of $50 \mathrm{mg} / \mathrm{L}$. The hydrolysis reaction is slow at ambient temperature and low acid concentration so that all the TBP has not yet hydrolyzed. Uranium is known to form compounds with DBP which have limited solubility. ${ }^{1-9}$ The solubility of $\mathrm{UO}_{2}(\mathrm{DBP})_{2}$ has been reported to be $5.6 \times 10^{-4}$ in $0.2 \mathrm{M} \mathrm{HNO}_{3}$ and a solubility product constant was calculated to be $6.1 \times 10^{-11}$.,? Previous unpublished studies at SRTC have shown that at ambient temperature $\mathrm{U}$ does not precipitate from $6 \mathrm{~g} / \mathrm{L} \mathrm{U}$ solutions with $100 \mathrm{mg} \mathrm{DBP} / \mathrm{L}$ solution, but does precipitate when the concentration reaches $125 \mathrm{mg} \mathrm{DBP} / \mathrm{L}$ solution. ${ }^{9}$ If all the dissolved TBP were converted to DBP, the solution could reach $158 \mathrm{mg} \mathrm{DBP} / \mathrm{L}$ solution. However, DBP is also hydrolyzed slowly to MBP which reduces the maximum attainable concentration. In addition, $U$ will precipitate at lower concentrations. The present concentration is $50-60 \mathrm{mg} / \mathrm{L}$ based on analyses of past samples of the solution with high uncertainty. Possible precipitation represents a nuclear criticality concern. A better understanding and measurement of the solubility limits for the U-HNO ${ }_{3}$-DBP system are needed to establish safety and operating limits for storage and operations.

Another concern is the large variability in analyses for DBP in the EU solution. Measurement of the concentration of DBP in the stored EU solution has been tracked over the past several years and found to average about $60 \mathrm{mg} / \mathrm{L} \pm 20 \mathrm{mg} / \mathrm{L}$. This large variability in analytical results affects the setting of operating limits and could result in uncertainty in whether the operating limit has been exceeded or not. Work was done to identify the uncertainty in analyses for DBP in the existing EU solutions.

\section{Experimental}

Solutions were prepared with reagent grade $\mathrm{HNO}_{3}$ and uranyl nitrate hexahydrate (UNH) and with $98 \%$ pure DBP solution obtained from Aldrich. Stock solutions of UNH and DBP were prepared in glass volumetric flasks with $0.5 \mathrm{M} \mathrm{HNO}_{3}$ prepared from $15.7 \mathrm{M}$ acid. The $\mathrm{UNH}$ solution containing $150 \mathrm{~g} / \mathrm{L} \mathrm{U}$ was prepared by dissolving $79.13 \mathrm{~g}$ of UNH solids in a $250 \mathrm{~mL}$ volumetric flask using $0.5 \mathrm{M} \mathrm{HNO}_{3}$ and diluting to the mark. The DBP solution was prepared by dissolving $0.2792 \mathrm{~g}$ of DBP in a $100 \mathrm{~mL}$ glass volumetric flask using $0.5 \mathrm{M}$ $\mathrm{HNO}_{3}$ and diluting to the mark. The concentration of DBP based on $98 \%$ purity is $2736 \mathrm{mg} / \mathrm{L}$. Duplicate analyses of the DBP stock solution gave an average concentration of $2700 \pm 10 \mathrm{mg} / \mathrm{L}$. The stock solutions were then used to prepare test solutions. Solubility in the $\mathrm{UO}_{2}\left(\mathrm{NO}_{3}\right)_{2}-\mathrm{HNO}_{3}-\mathrm{H}_{2} \mathrm{O}$ system was approached in two principal ways: precipitation and dissolution of known solids.

\section{Precipitation Tests}

Precipitation tests were done at ambient temperature $\left(22-23^{\circ} \mathrm{C}\right)$ and at $0^{\circ} \mathrm{C}$. Tests were carried out by preparing the solutions, and by allowing the solutions to sit in a hood at ambient temperature or in a constant temperature bath at $0^{\circ} \mathrm{C}$. The samples were examined daily to see if precipitation had occurred. If precipitation of solids occurred in the test, samples were taken to analyze the DBP concentration remaining in solution. The quantity of solids precipitated was small so that the concentrations of $U$ and acid should not be significantly affected. The intent of the test is to add enough DBP to be near or above the solubility limit. If the components are near the solubility limit, super-saturation can occur, which results in slow solids formation. Solution preparation is 
shown below for two $0^{\circ} \mathrm{C}$ tests and one ambient temperature test. In all cases, the $\mathrm{HNO}_{3}$ added was solution with the desired final concentration, either $0.1 \mathrm{M}, 0.3 \mathrm{M}$, or $0.5 \mathrm{M}$.

The solutions were prepared in glass vials with Teflon liners in the caps to prevent adsorption of DBP by the plastic. The total solution volume in the vials was $25 \mathrm{~mL}$ in all cases. Table 1 shows preparation of the first $0^{\circ} \mathrm{C}$ test. The quantity of $\mathrm{DBP}$, added during the first attempt at preparing samples for the $0^{\circ} \mathrm{C}$ test, was too high and resulted in immediate precipitation in all cases where $U$ was present. The samples were placed in the constant temperature bath at $0^{\circ} \mathrm{C}$ for several days before sampling and analysis. The DBP analyses are shown in the table as well. Two blanks were included as checks on the analyses.

Table 1. Solution Preparation for First $0^{\circ} \mathrm{C}$ Temperature Tests

\begin{tabular}{|r|r|r|r|r|r|r|r|}
\hline \multicolumn{4}{|c|}{ Solution Preparation } & \multicolumn{3}{|c|}{ Calculated Concentrations } & Analyses \\
\hline $\mathrm{mL}$ HNO3 & $\mathrm{mLU}$ & $\mathrm{mL}$ DBP & $\mathrm{mL}$ H2O & HNO3,M & U, g/L & DBP, $\mathrm{ppm}$ & DBP, $\mathrm{ppm}$ \\
\hline 20 & 0 & 1 & 4 & 0.1 & 0 & 109 & 108 \\
\hline 15 & 1 & 1 & 8 & 0.1 & 6 & 109 & 69 \\
\hline 13.125 & 1 & 1.375 & 9.5 & 0.1 & 6 & 150 & 71 \\
\hline 11.25 & 1 & 1.75 & 11 & 0.1 & 6 & 192 & 67 \\
\hline 7.5 & 2 & 1.5 & 14 & 0.1 & 12 & 164 & 74 \\
\hline 5 & 2 & 2 & 16 & 0.1 & 12 & 219 & 63 \\
\hline 2.5 & 2 & 2.5 & 18 & 0.1 & 12 & 274 & 72 \\
\hline 23.25 & 0 & 1.75 & 0 & 0.5 & 0 & 192 & 200 \\
\hline 21.75 & 1 & 2.25 & 0 & 0.5 & 6 & 246 & 99 \\
\hline 21.25 & 1 & 2.75 & 0 & 0.5 & 6 & 301 & 99 \\
\hline 20.75 & 1 & 3.25 & 0 & 0.5 & 6 & 356 & 93 \\
\hline 20.75 & 2 & 2.25 & 0 & 0.5 & 12 & 246 & 84 \\
\hline 20.25 & 2 & 2.75 & 0 & 0.5 & 12 & 301 & 88 \\
\hline 19.75 & 2 & 3.25 & 0 & 0.5 & 12 & 356 & 87 \\
\hline
\end{tabular}

The second test at $0^{\circ} \mathrm{C}$ was prepared by first diluting the $2736 \mathrm{mg} / \mathrm{L}$ solution to $1000 \mathrm{mg} / \mathrm{L}$ to allow more accurate volume measurement. Table 2 shows solution preparation along with the calculated concentrations and the precipitation results to date. Precipitation has not occurred in most of the samples.

Table 3 shows solution preparation and calculated values along with the observed precipitation times at ambient temperature.

\section{Dissolution of Solids}

Solid $\mathrm{UO}_{2}(\mathrm{DBP})_{2}$ was prepared by dissolving $9.97 \mathrm{~g}$ of $\mathrm{UNH}$ in $50 \mathrm{~mL}$ of deionized (DI) water and adding DBP prepared by washing $30 \mathrm{~mL}$ of a 50-50 mixture of DBP/MBP (monobutyl phosphate) three times with 10 $\mathrm{mL}$ portions of DI water. The MBP is highly water soluble compared to DBP and should be removed by the water washes. The small volume of water washes minimizes the loss of DBP due to solubility. Yellow solids separated immediately upon addition of DBP. The solids were sticky and were separated from the solution by filtration. The solids were dissolved in a small quantity of hot 2-ethylhexanol and reprecipitated by cooling 
Table 2. Solution Preparation for Second $0^{\circ} \mathrm{C}$ Temperature Tests

\begin{tabular}{|c|c|c|c|c|c|c|c|}
\hline \multicolumn{4}{|c|}{ Solution Preparation } & \multicolumn{3}{|c|}{ Calculated Concentrations } & Time to \\
\hline $\mathrm{mL}$ HNO3 & mLU & \begin{tabular}{l|l|}
$\mathrm{mL} D B P$ &
\end{tabular} & $\mathrm{mLH} 2 \mathrm{O}$ & $\mathrm{HNO} 3, \mathrm{M}$ & $\mathrm{U}, \mathrm{g} / \mathrm{L}$ & DBP, ppm & Precipitate \\
\hline 20 & 0 & 1 & 4 & 0.1 & 0 & 40 & Blank \\
\hline 15 & 1 & 1 & 8 & 0.1 & 6 & 40 & NoPpt \\
\hline T3.125 & 1 & 1.375 & 9.5 & 0.1 & 6 & 55 & No Ppt \\
\hline 11.25 & 1 & 1.75 & 11 & 0.1 & 6 & 70 & No Ppt \\
\hline 7.5 & 2 & 7.5 & 14 & 0.1 & 12 & 60 & No Ppt \\
\hline 5 & 2 & 2 & 16 & 0.1 & 12 & 80 & NoPpt \\
\hline 2.5 & 2 & 2.5 & 78 & 0.1 & 12 & 100 & NoPpt \\
\hline 23.25 & 0 & 1.75 & 0 & 0.5 & 0 & 70 & Blank \\
\hline 21.75 & 1 & 2.25 & 0 & 0.5 & 6 & 90 & No Ppt \\
\hline 21.25 & 1 & 2.75 & 0 & 0.5 & 6 & 110 & No Ppt \\
\hline 20.75 & 1 & 3.25 & 0 & 0.5 & 6 & 130 & 7 days \\
\hline 20.75 & 2 & 2.25 & 0 & 0.5 & 12 & 90 & No Ppt \\
\hline 20.25 & 2 & 2.75 & 0 & 0.5 & 12 & 170 & No Ppt \\
\hline 19.75 & 2 & 3.25 & 0 & 0.5 & 12 & 130 & 8 days \\
\hline
\end{tabular}

* No Ppt in 32 days at temperature

Table 3. Solution Preparation for Ambient Temperature Tests

\begin{tabular}{|c|c|c|c|c|c|c|c|}
\hline \multicolumn{4}{|c|}{ Solution Preparation } & \multicolumn{3}{|c|}{ Calculated Concentrations } & Time to \\
\hline$\overline{\mathrm{mL}} \mathrm{HNO}$ & mLU & $\mathrm{mL} D B P$ & $\overline{m L} H_{20}$ & HNO3,M & $U, g / L$ & DBP, ppm & Precipitate \\
\hline 15 & $\pi$ & 1 & 8 & 0.1 & 6 & 109 & NoPpt \\
\hline 70 & 2 & 1 & 12 & 0.1 & 12 & 109 & 56 days \\
\hline 5 & 3 & 1 & 16 & 0.1 & 18 & 109 & 56 days \\
\hline of & 15 & 1 & 9 & 0.1 & 90 & 109 & 35 days \\
\hline 78.33 & 1 & 3 & 2.67 & 0.3 & 6 & 328 & Tmmediate \\
\hline 16.67 & 2 & 3 & 3.33 & 0.3 & 12 & 328 & Tmmediate \\
\hline 15 & 3) & 3 & 4 & 0.3 & 78 & 328 & Tmmediate \\
\hline 0 & 15 & 3 & 7 & 0.3 & 90 & 328 & 16 days \\
\hline 19 & 1 & 5 & 0 & 0.5 & 6 & 547 & Immediate \\
\hline 18 & 2 & 5 & 0 & 0.5 & 12 & 547 & Immediate \\
\hline 77 & 3 & 5 & 0 & 0.5 & 18 & 547 & Tmmediate \\
\hline 5 & 15 & 5 & 0 & 0.5 & 90 & 547 & Overnight \\
\hline
\end{tabular}

* No Ppt in $>60$ days at temperature

with an ice bath. The resulting solids were filtered and dried in air. Yellow powder was obtained after drying ( $9.5 \mathrm{~g}, 72 \%$ yield). The $\mathrm{x}$-ray pattern of the solids was similar to that of Pu DBP with no indication of more than one phase. Thermogravimetric analysis of the solids resulted in a weight loss of $34.4 \%$ starting at $210^{\circ} \mathrm{C}$ and complete by $274^{\circ} \mathrm{C}$. The total weight loss was $37.2 \%$ at $315^{\circ} \mathrm{C}$. Thermogravimetric studies show that TBP decomposes when heated with loss of butyl groups complete at about $268^{\circ} \mathrm{C} .^{10}$ The product resulting from pyrolysis was given as $\mathrm{H}_{4} \mathrm{P}_{2} \mathrm{O}_{7} .{ }^{10}$ Based on that information the weight loss associated with formation of $\mathrm{UO}_{2} \mathrm{H}_{2} \mathrm{P}_{2} \mathrm{O}_{7}$ would be $35.2 \%$ and loss of a water molecule from that compound to give $\mathrm{UO}_{2} \mathrm{P}_{2} \mathrm{O}_{6}$ could occur at 
higher temperatures resulting in a weight loss of $37.8 \%$. The data indicated the desired compound had been prepared. These solids were then used in subsequent dissolution tests at $10^{\circ} \mathrm{C}$ and $30^{\circ} \mathrm{C}$.

One half gram of solids were placed in glass vials with various amounts of UNH stock solution, the appropriate concentration of acid, and DI water to obtain the desired concentrations. In addition, vials were prepared with water and the three acid concentrations without any U present. The total volume, added to each vial was 25 $\mathrm{mL}$. The vials were placed in a constant temperature bath at the desired temperature. Periodic samples were taken for DBP analysis to determine if equilibrium had been reached. When equilibrium was attained, samples were taken and analyzed for DBP, $U$, and free acid. The samples taken for analysis from the bath at $30^{\circ} \mathrm{C}$ were diluted with an equal volume of $0.5 \mathrm{M} \mathrm{HNO}_{3}$ to ensure that precipitation did not occur when the samples cooled to ambient temperature. Solution preparation for both tests was the same as shown in Table 4. Blank samples of DI water were submitted with all samples from this set. In addition, some solutions with known initial amounts of DBP in 6-18 $\mathrm{g} / \mathrm{L} \mathrm{U}$ were prepared as standards and submitted along with the samples.

Table 4. Solution Preparation for $\mathrm{UO}_{2}(\mathrm{DBP})_{2}$ Solid Dissolution

\begin{tabular}{|r|r|r|r|r|}
\hline \multicolumn{3}{|c|}{ Solution } & \multicolumn{2}{c|}{ Calculated } \\
\hline \multicolumn{3}{|c|}{ Preparation } & \multicolumn{2}{c|}{ Concentrations } \\
\hline mL HNO3 & $\mathrm{mL} U$ & $\mathrm{~mL}$ H2O & HNO3,M & U, g/L \\
\hline 0 & 0 & 25 & 0 & 0 \\
\hline 25 & 0 & 0 & 0.1 & 0 \\
\hline 25 & 0 & 0 & 0.3 & 0 \\
\hline 25 & 0 & 0 & 0.5 & 0 \\
\hline 20 & 1 & 4 & 0.1 & 6 \\
\hline 15 & 2 & 12 & 0.1 & 12 \\
\hline 10 & 3 & 16 & 0.1 & 18 \\
\hline 0 & 15 & 9 & 0.1 & 90 \\
\hline 23.30 & 1 & 0.67 & 0.3 & 6 \\
\hline 21.70 & 2 & 1.33 & 0.3 & 12 \\
\hline 20 & 3 & 2 & 0.3 & 18 \\
\hline 0 & 15 & 10 & 0.3 & 90 \\
\hline 24 & 1 & 0 & 0.5 & 6 \\
\hline 23 & 2 & 0 & 0.5 & 12 \\
\hline 22 & 3 & 0 & 0.5 & 18 \\
\hline 10 & 15 & 0 & 0.5 & 90 \\
\hline
\end{tabular}

\section{Analyses}

Analysis for $U$ in solution was done by the Chem Check instrument, which utilizes $U$ phosphorescence. Free acid analyses were done by the standard method in Analytical Development Section. DBP analyses were done by ion chromatographic analysis (IC). Considerable effort was made to improve the DBP analysis method to obtain reproducible results with the lowest uncertainty. Samples without $U$ or high nitrate ion can be run without significant pretreatment. However, $U$ and high nitrate can interfere with the analysis. Nitrate is also an anion which at high concentrations binds with more ion exchange sites on the analytical column causing DBPto elute in the void volume. Uranium complexes DBP so strongly $\left(\beta_{1}=1 \times 10^{4}\right)^{8}$ that a portion of the DBP is not present as an anion in the eluant, causing the results to be low. Both effects were overcome by pretreatment involving extraction of DBP from the aqueous samples with 2-ethylhexanol followed by back-extraction into 1 $\mathrm{M} \mathrm{NaOH}$. The back-extracted solution was then put through ion exchange cartridges to remove the sodium ion and protonate $\mathrm{DBP}^{-}$to HDBP. Optimum instrumental analysis was achieved in a $\mathrm{pH}$ range between 0 and 3. A 
check for $\mathrm{U}$ and $\mathrm{NO}_{3}{ }^{-}$effects. Spike recovery was also done on random samples. Spike recoveries of 83 to 91 $\%$ were consistently observed with most of the recoveries being between 87 and $89 \%$.

\section{Results and Discussion}

The solubility of $\mathrm{U}$ in $\mathrm{HNO}_{3}$ solutions containing DBP is expected to be a function of acid concentration, and $\mathrm{U}$ concentration as can be seen from the reaction governing precipitation (equation 1).

$\mathrm{UO}_{2}^{2+}+2 \mathrm{HDBP} \leftrightarrow \mathrm{UO}_{2}(\mathrm{DBP})_{2 \text { solid }}+2 \mathrm{H}^{+}$

Temperature is also a variable since soubility generally increases with increasing temperature. The reaction given above is the overall reaction to yield a precipitate. There are actually several reactions and associated equilibrium constants involved as shown in equations $2-4 .^{3}$

$$
\begin{array}{ll}
\mathrm{HDBP} \leftrightarrow \mathrm{H}^{+}+\mathrm{DBP}^{-} & \mathrm{K}_{\mathrm{a}}=\left[\mathrm{H}^{+}\right]\left[\mathrm{DBP}^{-}\right] /[\mathrm{HDBP}] \\
\mathrm{UO}_{2}{ }^{2+}+\mathrm{DBP}^{-} \leftrightarrow \mathrm{UO}_{2}(\mathrm{DBP})^{1+} & \beta_{1}=\left[\mathrm{UO}_{2}\left(\mathrm{DBP}^{1+}\right] /\left[\mathrm{UO}_{2}{ }^{2+}\right][\mathrm{DBP}-]\right. \\
\mathrm{UO}_{2}(\mathrm{DBP})^{1+}+\mathrm{DBP}^{-} \leftrightarrow \mathrm{UO}_{2}(\mathrm{DBP})_{2 \text { solution }} & \beta_{2}=\left[\mathrm{UO}_{2}(\mathrm{DBP})_{2}\right] /\left[\mathrm{UO}_{2}(\mathrm{DBP})^{1+}\right]\left[\mathrm{DBP}^{-}\right]
\end{array}
$$

where the brackets in the equilibrium constants are for molal activity. At low concentrations of reactants, the activity is the same as the molal concentration because the activity coefficients are equal to one. The activity coefficients are not equal to one for the solutions being studied especially at the highest acid and $U$ concentrations. The stability constant for the first step $\left(\beta_{1}\right)$ is reported to be $10^{4}$, but no value is reported for the second step. ${ }^{9}$ The equation to define the solubility of the solid and solubility product constant $\left(\mathrm{K}_{\mathrm{sp}}\right)$ for this reaction are shown in equation 5.

$$
\mathrm{UO}_{2}(\mathrm{DBP})_{2 \text { solid }} \leftrightarrow \mathrm{UO}_{2}^{2+}+2 \mathrm{DBP}^{-} \quad \mathrm{K}_{\mathrm{sp}}=\left[\mathrm{UO}_{2}^{2+}\right]\left[\mathrm{DBP}^{-}\right]^{2}
$$

Two values have been reported for $\mathrm{K}_{\mathrm{sp}}$ in the literature which differ by a factor of $10 .^{7,8}$ A further complication is that two values are also reported for the acid dissociation constant $\left(\mathrm{K}_{2}\right)$ for $\mathrm{HDBP}$, which differ by a factor of $>5 .{ }^{11,12}$ One of the values for $\mathrm{K}_{\mathrm{sp}}$ was calculated using the higher value for $\mathrm{K}_{\mathrm{a}}$ (equation 5), although the lower value is believed to be correct. Consequently, the literature data could not be used for calculation of the information required here.

The results from work on improvement of DBP analyses by ion chromatography will be presented first since the uncertainties shown in the analyses affect the interpretation of the solubility studies. Significant improvements were made during the course of these studies in the reproducibility and accuracy of DBP analyses. The principal problem was encountered only when $U$ was present in solution. Initial results were scattered and could not be replicated at times. Replicates of 14 samples ranged from no difference to almost 26 $\%$ difference. A DI water blank was reported to contain $64 \mathrm{mg} / \mathrm{L}$ DBP and samples where DBP was known to be $110 \mathrm{mg} / \mathrm{L}$ varied from 58 to $95 \mathrm{mg} / \mathrm{L}$. Submission of blanks with only DBP and standards with known quantities of $U$ and DBP were included with other solubility samples to determine when problems were occurring and to establish a basis for reproducibility and uncertainty. Improvements made in sample pretreatment and elution have improved overall results although periodic variations do require samples to be analyzed a second time. Table 5 shows the results from analysis of standard samples nominally containing 50 $\mathrm{mg} / \mathrm{L} \mathrm{DBP}$ with $6 \mathrm{~g} / \mathrm{L} \mathrm{U}$ and $0.1 \mathrm{M} \mathrm{HNO} 3$ and $75 \mathrm{mg} / \mathrm{L} \mathrm{DBP}$ with $18 \mathrm{~g} / \mathrm{L} \mathrm{U}$ and $0.5 \mathrm{M} \mathrm{HNO}_{3}$. These results are very good because they were analyzed soon after submission, a standard sample was analyzed at the same time for spike recovery, and attention was paid to the chromatogram from the instrument to insure the correct peak is evaluated. Experience with the pretreatment method has also led to improved results. 
Table 5. Analytical Results for Standard Samples

\begin{tabular}{|l|l|l|l|}
\hline $\begin{array}{l}\text { DBP in Standard, } \\
\mathbf{m g} / \mathbf{L}\end{array}$ & DBP Analysis, mg/L & $\begin{array}{l}\text { DBP in Standard, } \\
\mathbf{m g} / \mathbf{L}\end{array}$ & DBP Analysis, $\mathbf{m g} / \mathbf{L}$ \\
\hline 50 & 52 & 75 & 71 \\
\hline 50 & 53 & 75 & 74 \\
\hline 50 & 53 & 75 & 77 \\
\hline 50 & 53 & 75 & 77 \\
\hline 50 & 54 & 75 & 77 \\
\hline 50 & 54 & 75 & 78 \\
\hline 50 & 54 & 75 & 80 \\
\hline 50 & 54 & 75 & 81 \\
\hline Average & 53.4 & Average & 76.9 \\
\hline Standard Deviation & 0.7 & Standard Deviation & 3.2 \\
\hline \% Standard Deviation & 1.4 & \% Standard Deviation & 4.1 \\
\hline
\end{tabular}

Table 6 shows the results of analysis of plant solutions taken at two different times which were split into five separate samples and interspersed with each other as well as some other plant samples. Note that one sample in each set was replicated so that six results are presented in the table. These samples had not been analyzed previously.

Table 6. Replicate Analyses of Plant EUS Samples

\begin{tabular}{|l|r|l|r|}
\hline EUS Sample Date $2 / 7 / 98$ & \multicolumn{2}{|l|}{ EUS Sample Date $3 / 29 / 98$} \\
\hline Sample Number & DBP, mg/L & Sample Number & DBP, $\mathrm{mg} / \mathrm{L}$ \\
\hline $3-107238$ & 34 & $3-107240$ & 45 \\
\hline $3-107239$ & 32 & $3-107241$ & 39 \\
\hline $3-107458$ & 35 & $3-107462$ & 48 \\
\hline $3-107460$ & 37 & $3-107462$ & 44 \\
\hline $3-107460$ & 35 & $3-107463$ & 44 \\
\hline $3-107461$ & 40 & $3-107464$ & 43 \\
\hline Average & 35.5 & Average & 43.8 \\
\hline Standard Deviation & 2.7 & Standard Deviation & 2.9 \\
\hline Percent Std. Dev. & 7.6 & Percent Std. Dev. & 6.6 \\
\hline
\end{tabular}

Note that the percent standard deviation is slightly different for the two sets of samples, but is less than $10 \%$ in both cases. Table 7 shows the averages of the split samples combined with several samples taken last year, two of which were analyzed earlier. The percent standard deviation is much higher and is attributed to a combination of small number of samples analyzed by the improved method, difference in samples, and the analytical error for the improved method. This does not appear to be a significant improvement in the overall uncertainty observed previously, even though the analytical error for the method is low. It should be possible to reduce the uncertainty in EUS sample results by submitting multiple samples instead of a single sample to allow averaging of the results. Three samples will allow statistics to be used to discard analyses or to signal that the sample should be reanalyzed. Submission of a known standard along with the samples can help determine whether problems are being encountered in the analytical method or in sampling and sample handling. 
Table 7. Combined Error for EUS Samples

\begin{tabular}{|l|l|l|}
\hline Sample Date & DBP Analysis, $\mathrm{mg} / \mathrm{L}$ & Comments \\
\hline $6 / 4 / 97$ & 43 & One sample \\
\hline $8 / 6 / 97$ & 57 & One Sample \\
\hline $12 / 2 / 97$ & 67 & One sample \\
\hline $2 / 7 / 98$ & 35.5 & Average \\
\hline $3 / 29 / 98$ & 43.8 & Average \\
\hline Average & 49.3 & \\
\hline Standard Deviation & 12.6 & \\
\hline Percent Std. Dev. & 25.5 & \\
\hline
\end{tabular}

The results from tests at 0 and $23^{\circ} \mathrm{C}$ were shown in Tables 1-3. The results from the first set of $0^{\circ} \mathrm{C}$ tests show that within the analytical uncertainties there is no difference in the DBP concentrations with 6 or $12 \mathrm{~g} / \mathrm{L} \mathrm{U}$ at $0.1 \mathrm{M} \mathrm{HNO}_{3}$. The final DBP concentration is the same regardless of the starting DBP concentration. Reif noted that within his experimental conditions there was no difference in precipitation threshold for 3 or $6 \mathrm{~g} / \mathrm{L} \mathrm{U}$ solutions with $0.1 \mathrm{M} \mathrm{HNO}_{3}{ }^{9}$ The concentration of $\mathrm{DBP}$ which can result in precipitation then is about $70 \mathrm{mg} / \mathrm{L}$ for both 6 and $12 \mathrm{~g} / \mathrm{L} U$ solutions at $0^{\circ} \mathrm{C}$. If this value is used as the safety limit with the operating limit set lower, the operating limit would be exceeded by one of the samples shown in Table 7. Therefore, the acidity must be increased to $0.5 \mathrm{M}$ to allow existing freeze protection measures to define the low temperature for the tanks. It is uncertain whether the data at $0.5 \mathrm{M} \mathrm{HNO}_{3}$ is different for 6 and $12 \mathrm{~g} / \mathrm{L} \mathrm{U}$. The $6 \mathrm{~g} / \mathrm{L}$ data has an average of $97 \mathrm{mg} / \mathrm{L}$ with a standard deviation of $3.5 \mathrm{mg} / \mathrm{L}$. The $12 \mathrm{~g} / \mathrm{L}$ data has an average of $86 \mathrm{mg} / \mathrm{L}$ with a standard deviation of $2.1 \mathrm{mg} / \mathrm{L}$. There is no difference in the numbers at 2 standard deviations.

Tables 2 and 3 show that super-saturation occurs in the solutions such that actual formation of solids is delayed for as much as several months when the DBP concentration exceeds the solubility limit. For example, the second set of $0^{\circ} \mathrm{C}$ samples has been in the constant temperature bath for more than 4 weeks with only two of the five samples, which should precipitate actually having solids present (this assumes Table 1 analyses are correct). The samples, which precipitated took 7 to 8 days before solids appeared although the solubility limit was exceeded by $34 \%$ and $50 \%$, respectively. Samples at $0.5 \mathrm{M} \mathrm{HNO}_{3}$ with $110 \mathrm{mg} / \mathrm{L}$ DBP added initially have $13 \%$ and $27 \%$ excess DBP, but show no solids yet. This data confirms that super-saturation is not a steady state condition and precipitation will eventually occur.

The analytical data for DBP in the solutions at $23^{\circ} \mathrm{C}$ were not reliable having been analyzed prior to recent improvements in the analytical method; they are not reported. Observations about the time of precipitation are valid. Figures 1-4 summarize remaining data for different temperatures and acid concentrations. The data for $90 \mathrm{~g} / \mathrm{L} \mathrm{U}$ is not shown in these figures to provide clarity. The DBP concentrations required for precipitation at $90 \mathrm{~g} / \mathrm{L}$ are higher than for the lower concentrations shown in the figures. This phenomenon is due either to the increased ionic strength or to the formation of the charged complex ion shown in equation 3 above. The ionic strength will change the activity coefficients affecting the activities in the system. High $U$ concentration increases the amount of DBP present in solution as the complex ion, $\mathrm{UO}_{2}(\mathrm{DBP})^{1+}$, thus more $\mathrm{DBP}$ is needed in solution to initiate precipitation.

Figures 1 and 2 show there is little change in DBP concentration required for precipitation as the U concentration changes at a constant acid concentration except for samples with no initial $U$ present. Figures 3 
Figure 1.

\section{U-DBP Solubility vs. Temp. - 0.1M HNO3}

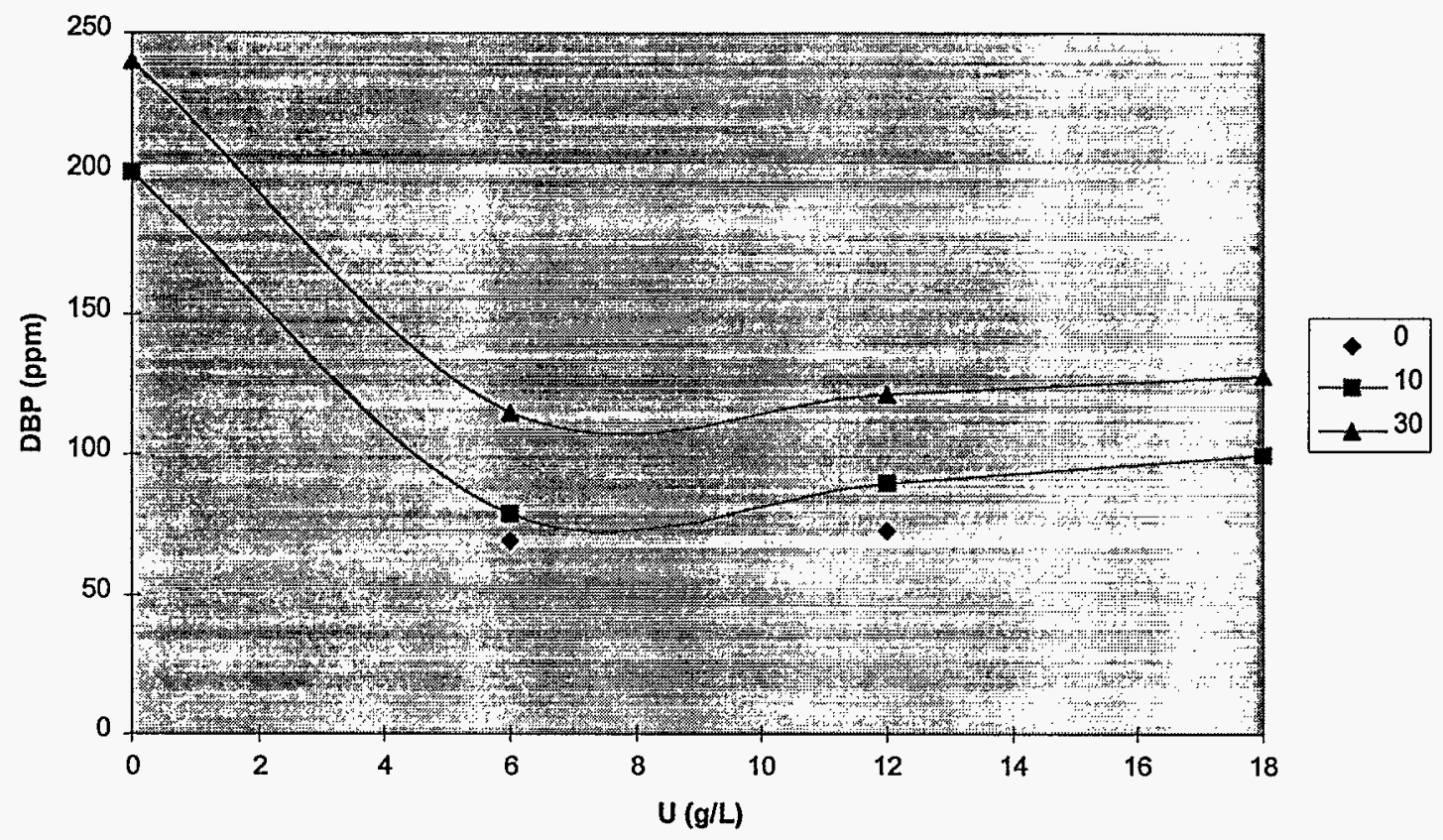

Figure 2.

U-DBP Solubility vs. Temp. - 0.5M HNO3

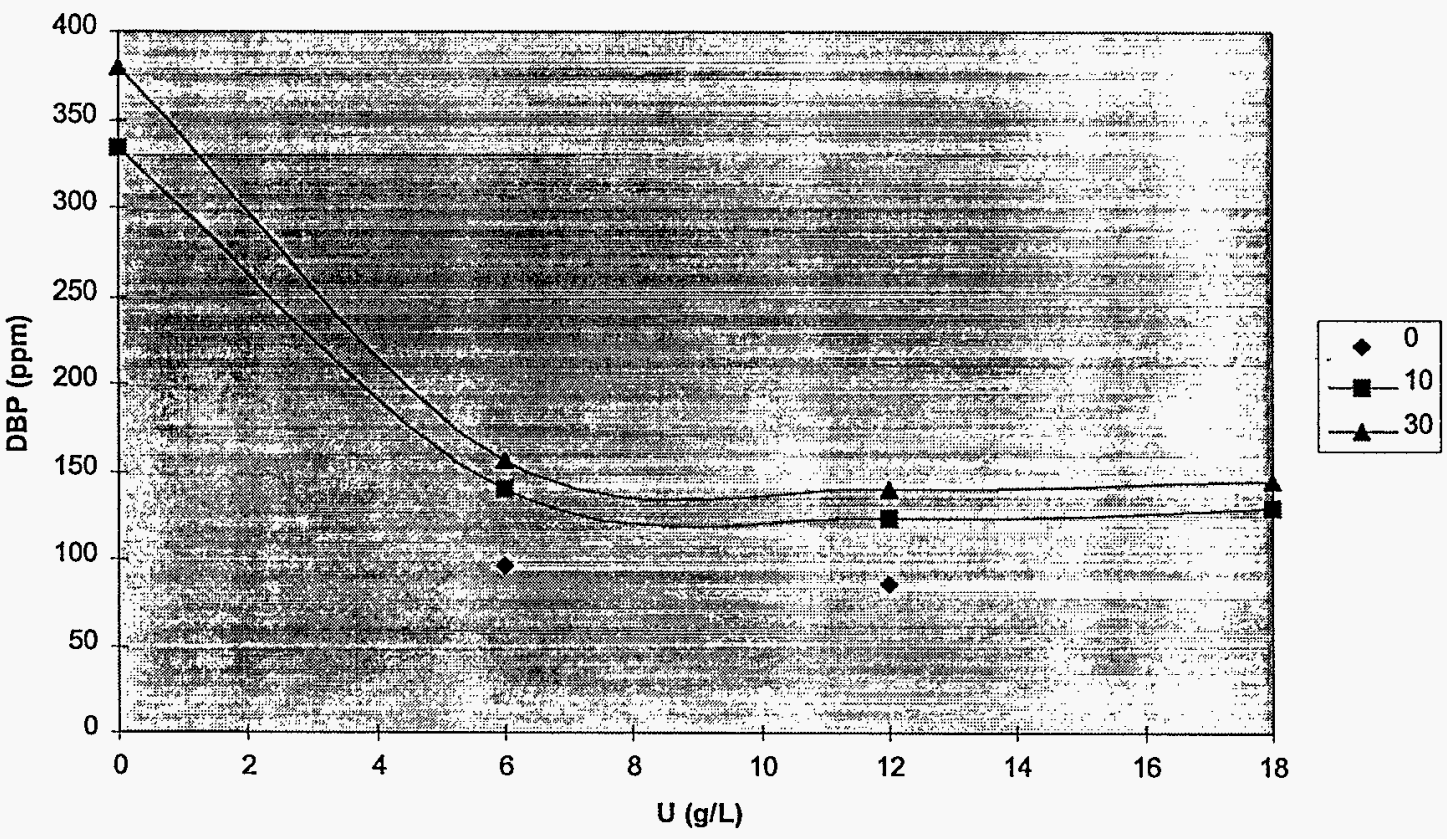


WSRC-TR-98-00188

Rev. 0

Figure 3.

\section{U-DBP Solubility vs. Acid Concentration - 10 deg C}

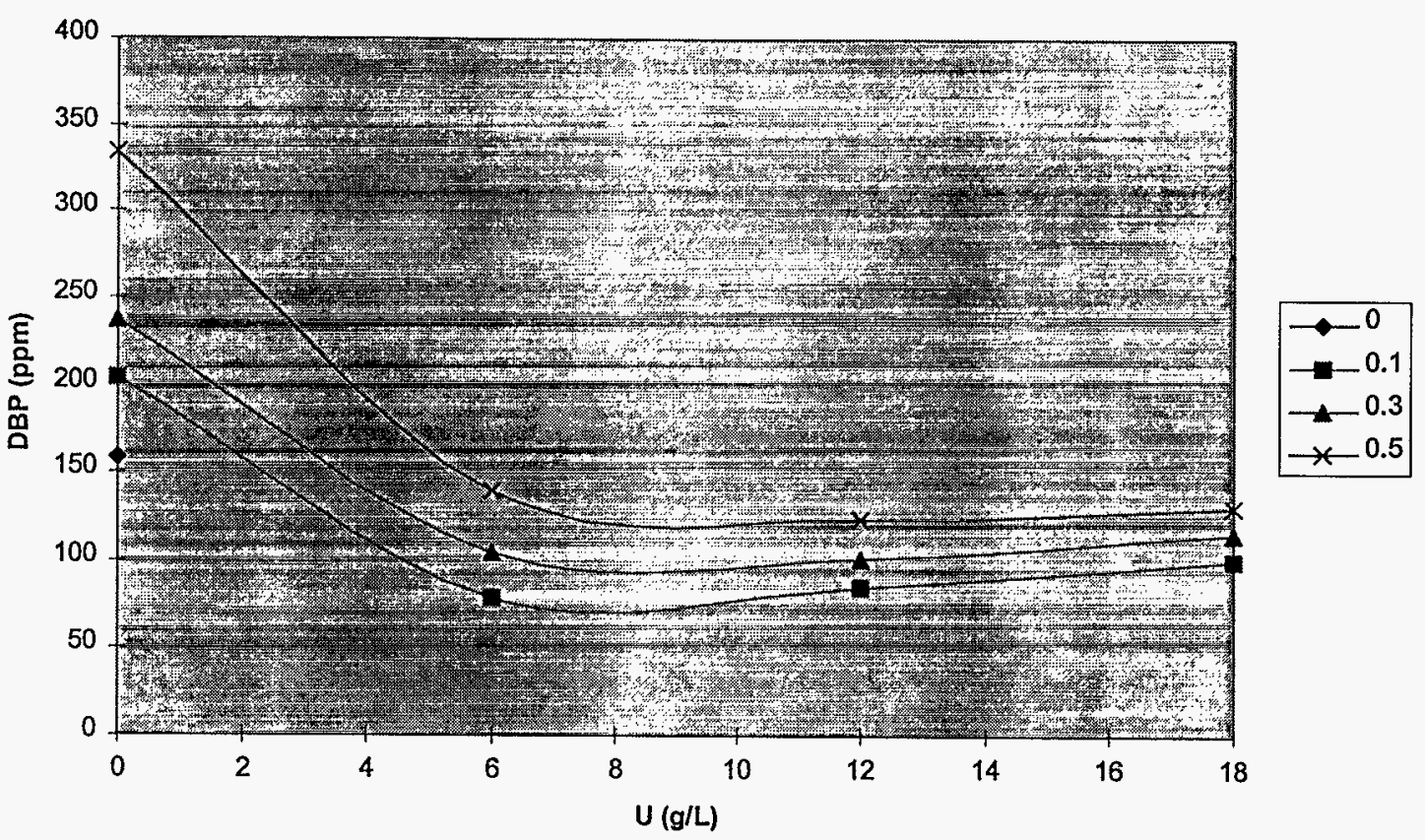

Figure 4.

U-DBP Solubility vs. Acid Concentration - $30 \mathrm{deg}$ C

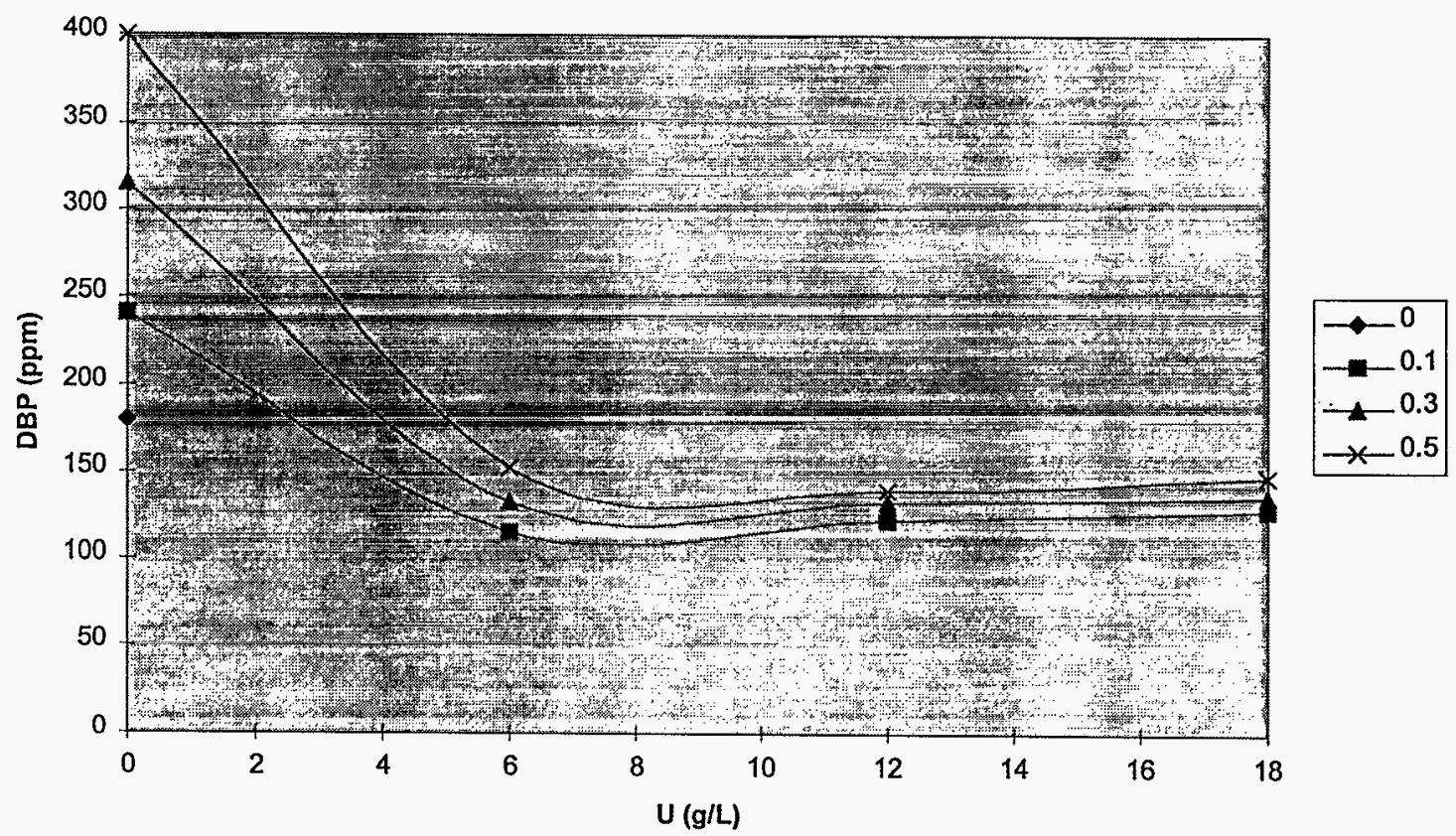


and 4 show that the shape of the curves change slightly at higher acidity such that the apparent minimum concentration of DBP occurs at $12 \mathrm{~g} / \mathrm{L}$ in $0.5 \mathrm{M} \mathrm{HNO}_{3}$ instead of $6 \mathrm{~g} / \mathrm{L}$ in $0.1 \mathrm{M} \mathrm{HNO}_{3}$. In the range of acid concentration tested, increasing the acid concentration by a factor of 5 from $0.1 \mathrm{M}$ to $0.5 \mathrm{M}$ increases the DBP concentration required for precipitation by a maximum factor of 2 . That much increase is only observed at the lowest concentration. The increase is less at 12 and $18 \mathrm{~g} / \mathrm{L} \mathrm{U}$. Temperature appears to have the largest effect at low acidity, but the effect is reduced at higher acidity.

The data in the figures and tables can be used to establish limits for temperature, acid concentration and DBP concentration required to maintain safety during storage. It is clear from Figures 1 and 2 that in the range of uranium concentrations anticipated during storage and processing, $6-12 \mathrm{~g} / \mathrm{L}$, the data at $0.5 \mathrm{M} \mathrm{HNO}_{3}$ and $0^{\circ} \mathrm{C}$ should be used to establish safety limits. Establishing limits based on this data allows existing freeze protection measures to ensure that precipitation will not occur.

\section{Conclusions and Recommendations}

The tests have shown that U-DBP solids will precipitate at concentrations potentially attainable during storage of enriched uranium solutions. Evaporation of the existing EUS solution without additional acidification will result in the precipitation of U-DBP solids; the same potential exists for evaporation of unwashed 1CU solutions. The most important variables of interest for present plant operations are $\mathrm{HNO}_{3}$ and $\mathrm{DBP}$ concentrations. Uranium concentrations of 6 to $18 \mathrm{~g} / \mathrm{L}$ do not significantly affect the DBP concentration at which precipitation can occur. Temperature is also an important variable controlling precipitation. Existing freeze protection measures should be relied on to maintain temperature above freezing. The data obtained in these tests can be used to set operating and safety limits for the plant. It is recommended that the data for $0^{\circ} \mathrm{C}$ with $0.5 \mathrm{M} \mathrm{HNO}_{3}$ be used for setting the limits. A safety limit (Double Contingency Analysis) of $80 \mathrm{mg} / \mathrm{L}$ is 3 standard deviations below the average at $12 \mathrm{~g} / \mathrm{L}$ and should be adequate to ensure that precipitation will not occur. The data shows that super-saturation can occur when the DBP concentration is as much as $50 \%$ above the solubility limit. However, super-saturation is not a steady state condition and precipitation will eventually occur. Therefore, super-saturation cannot be relied on for maintaining nuclear criticality safety.

The analytical method for determining DBP concentration in U solutions was improved so that analyses for a solution are accurate to within $10 \%$. However, the uncertainty of analytical results for periodic samples of the existing EUS solutions was only reduced from $30 \%$ to $25 \%$. Thus, sampling appears to be the largest portion of the uncertainty for EUS sample results. The analytical method can be transferred to the plant analytical labs for more routine analysis of samples. It is recommended that more frequent sampling of the EUS tank be done. More than one sample (preferably 3) should be submitted in conjunction with a standard containing both 6-18 $\mathrm{g} / \mathrm{L} U$ and $50-80 \mathrm{mg} / \mathrm{L} \mathrm{DBP}$. The analytical results obtained should be treated statistically to obtain an average value with outlying values excluded based on statistical tests.

\section{References}

1. D. Smith. "The Salts of Organic Phosphorus Acids - I. The Infra-red Spectra of Salts of Di-n-Butyl Phosphate", J. Inorg. Nucl. Chem., 9, 150-154 (1959).

2. W. H. Baldwin and C. E. Higginson. "Complexes of Dibutyl Phosphoric Acid", J. Inorg. Nucl. Chem., 17, 364-366 (1961).

3. J. Kennedy and A. M. Deane. "The Preparation and Spectrum of Tetrabutyl Ammonium Uranyl Dibutyl Phosphate", J. Inorg. Nucl. Chem., 20, 295-299 (1961). 
4. H. T. Hahn, E. M. Vander Wall, R. H. Ray, and R. G. Butzman. Removal of Tributyl Phosphate and its Degradation Products from Acidified Uranyl Nitrate Solutions, IDO-14630, Phillips Petroleum Co., Idaho Chemical Processing Plant (1964).

5. P. G. Krutikov and A. S. Solovkin. "Di-n-Butyl Phosphato)-Compounds of Uranyl", Russ. J. Inorg. Chem., $15,825-827(1970)$.

6. E. G. Teretin, N. N. Shesterikov, P. G. Krutikov, and A. S. Solovkin. "Infrared Spectroscopic Study of Din-butylphosphato-compounds of Uranyl", Russ. J. Inorg. Chem., 16, 416-418 (1970).

7. A. S. Solovkin. "Mono- and Di-n-Butylphosphates of Certain Metals Important in Regeneration Processes of Iradiated Nuclear Fuels", Soviet Radiochem., 24, 49-56 (1982).

8. J. Y. Pasquiou, J. Livet, M. Germain, and C. Musikas. Pu(IV)-Dibutylphosphate Complexes in the PUREX Process, CEA-CONF-9091, presented at Extraction 87, Dounreay, UK, June, 1987.

9. D. J. Reif, 1EU Solution Tolerance for Dibutylphosphate (DBP) (U), Internal Memo SRL-ATS-92-0157, March 27, 1992.

10. G. S. Barney and T. D. Cooper. The Chemistry of Tributyl Phosphate at Elevated Temperatures in the Plutonium Finishing Plant Process Vessels, WHC-EP-0737, Westinghouse Hanford Co., Richland, WA, 1994.

11. C. J. Hardy and D. Scargill. "Studies on Mono- and Di-n-Butylphosphoric Acids - II The Solubility and Distribution of Mono- and Di-n-Butylphosphoric Acids in Aqueous-Organic Solvent Systems", J. Inorg. Nucl. Chem., 11, 128-143 (1959).

12. W. D. Kumler and J. J. Eiler. "The Acid Strength of Mono and Diesters of Phosphoric Acid. The n-Alkyl Esters from Methyl to Butyl, the Esters of Biological Importance, and the Natural Guaidine Phosphoric Acids", J. Am. Chem. Soc., 65, 2355-61 (1943). 